\title{
Ausência de conflitos: relação entre religião e ciência na formação universitária
}

\section{No conflicts: religion and science as knowledge during academic experience}

\author{
Isabel FC Rayes ${ }^{1}$, João Eduardo Coin de Carvalho²
}

\begin{abstract}
RESUMO
Introdução: O presente trabalho, refere-se ao estudo sobre as representações entre diferentes formas de conhecimento, ciência e religião, junto aos alunos de Psicologia de uma universidade particular, laica, de São Paulo, verificando se o curso favorece ou não a formação de conflitos. O objetivo é verificar se os alunos são conduzidos à obtenção de novas posturas, novos modos de pensar, novas "vias do olhar". Métodos: Foram realizadas cinco entrevistas semi-abertas, baseadas num roteiro pré-estabelecido, com alunos do $3^{\circ}$ ano de Psicologia. Resultados: Para eles, embora o conhecimento associado à religião apresente-se como dogmático, surpreendentemente não conflitua com o conhecimento científico, oferecendo um conhecimento complementar. De um lado utilizam-se da religião para suprir necessidades de bem estar, proteção, meditação e como alimento para a alma. De outro, a ciência oferece um conhecimento mais concreto, sem interferir na fé, mas sem provocar convicções mais profundas. Acreditam que a ciência traz conflitos somente no começo da formação acadêmica, e aprendem a separar ciência da religião no decorrer do curso. O conhecimento, nestas duas modalidades, se apresenta como algo individual, não se percebendo sua dimensão social e interferências ideológicas. Conclusão: Concluímos que num curso superior, como nos cursos de Psicologia, há grandes dificuldades para a instalação de uma visão crítica em relação ao conhecimento, seja quanto às suas diferentes modalidades, seja quanto ao seu uso. Tal cenário indica a necessidade da formação de mais áreas de "conflito" na formação acadêmica, na direção de efetivamente conduzir a um profissional instrumentalizado para uma posição crítica também como cidadão.
\end{abstract}

Unitermos: Ciência, Religião, Educação, Conhecimento.

Citação: Rayes IFC, Carvalho JEC. Ausência de conflitos: relação entre religião e ciência na formação universitária. Rev Neurociencias 2005, 13(3): 128-132.

\section{SUMMARY}

Introduction: The aim of this work is studying students' representations of different ways of knowing, science and religion. We intend to verify if university experience can modify their relations with knowledge, improving new ways of realize their own lives. Methods: We have done 5 (five) semi-structured interviews with students from a Psychology Department in a private University sited in São Paulo. Results: Research reveals a representation of religion as offering a dogmatic knowledge, which, surprisingly, doesn't oppose the scientific knowledge, and, indeed, it's understood as a complementary knowledge. If religion can offer well being, protection, "food for our souls", science, on the other hand, offers a way of knowing based on facts. But this specificity of science is not enough to modify private beliefs as students learn to separate religion and science during their academic formation. Knowledge

Trabalho Realizado: Curso de Psicologia, Instituto de Ciências Humanas, Universidade Paulista - UNIP.

1 - Graduanda em Psicologia, Instituto de Ciências Humanas, UNIP-Universidade Paulista.

2 - Professor Titular do Curso de Psicologia, Instituto de Ciências Humanas, UNIP-Universidade Paulista, NECON - Núcleo de Estudos do Conhecimento (UNIFESP).

Endereço para Correspondência: João Eduardo Coin de Carvalho

Rua Japurá, 55 ap. 617.

São Paulo - SP

E-mail: joaocoin@yahoo.com

Trabalho recebido em 27/09/05. Aprovado em 04/10/05 
is presented as a private experience and they don't support the idea of a social and ideological process of producing knowledge. Conclusion: We conclude that it is very hard to Brazilian universities offer tools for constructing a critical understanding of knowledge. Such social scene claims for educational and political actions, which could create "conflicts" that lead students and professionals to a critical position as citizens.

\section{Keywords: Science, Religion, Education, Knowledge.}

Citação: Rayes IFC, Carvalho JEC. No conflicts: religion and science as knowledge during academic experience. Rev Neurociencias 2005, 13(3): 128-132.

\section{INTRODUÇÃO}

Costumamos ouvir que o homem é um animal espiritual. Homens e mulheres começaram a adorar deuses assim que se tornaram reconhecidamente humanos: criaram religiões ao mesmo tempo em que criaram obras de arte. Isso não foi apenas porque desejavam propiciar forças poderosas; essas fés primitivas exprimiam a perplexidade e o mistério que sempre parecem ter sido componentes essenciais da experiência humana neste belo, mas aterrorizante, mundo. Como a arte, a religião foi uma tentativa de encontrar sentido e valor na vida ${ }^{1}$.

Através das religiões o universo físico se organiza em torno da alma humana, indicando o esforço de pensar a realidade "a partir da exigência de que a vida faça sentido"'2. Contemporaneamente, o que ocorre com freqüência é que as mesmas perguntas religiosas do passado se articulam agora, travestidas por meio de símbolos secularizados e os deuses e esperanças religiosas vão se materializar em novos rótulos a que nos apegamos, ainda que insistamos em dizer que não somos "religiosos".

Armstrong ${ }^{1}$ afirma que em vez de se esperar que Deus descesse das alturas, deveríamos criar deliberadamente um sentido dele nela. Deus é um produto da imaginação criadora, como a poesia e a música, e, se Deus não existe, Ele, no entanto, é a mais importante realidade do mundo. A idéia de Deus formada numa geração por um conjunto de seres humanos pode não ter sentido em outra. A palavra Deus não contém uma idéia imutável, mas, ao contrário, contém todo um espectro de significados, alguns dos quais contraditórios ou até mutuamente exclusivos. Se a idéia de Deus não tivesse flexibilidade, não teria sobrevivido e se tornado uma das grandes idéias humanas. Sempre que um conceito de Deus deixou de ter sentido ou importância, foi discretamente abandonado e substituído por uma nova teologia.

No processo histórico através do qual nossa civilização se formou, recebemos uma herança simbólicoreligiosa a partir das tradições culturais dos gregos e dos romanos. Com estes símbolos vieram visões de mundos totalmente distintas, mas eles se amalgamaram, transformaram-se mutuamente, e vieram a florescer em meio às condições materiais de vida dos povos que os receberam².

Na Idade Média os símbolos do sagrado adquiriram uma densidade, uma concretude e uma onipresença que faziam com que o mundo invisível estivesse mais próximo e fosse mais sentido do que as próprias realidades materiais. Tudo girava em torno de um núcleo central, temática que unificava todas as coisas: o drama da salvação, o perigo do inferno, a caridade de Deus, levando aos céus as almas puras.

Entretanto, aos poucos, mas de forma constante, progressiva, crescente, os homens começaram a fazer coisas não previstas no receituário religioso. Não eram aqueles que ficavam na cúpula da hierarquia sagrada que as faziam. E nem aqueles que estavam condenados aos seus subterrâneos. Enquanto aos que estão em cima não lhes interessaria as mudanças, os que se acham muito por baixo gastam suas poucas energias na luta pela sobrevivência. De uma classe social que se encontrava em meio a estes extremos que surgiu uma nova e subversiva atitude econômica, que corroeu as coisas e os símbolos do mundo medieval. Em oposição aos cidadãos do mundo sagrado que haviam criado símbolos que thes permitia compreender a realidade como um drama e visualizar seu lugar dentro de sua trama, à nova classe interessavam atividades como produzir, comercializar, racionalizar o trabalho, viajar para descobrir novos mercados, obter lucros, criar riquezas.

O que acontece é que, ao surgirem problemas novos relativos à vida concreta, os homens são praticamente obrigados a inventar conceitos novos. Produziu-se então, uma nova orientação para o pensamento derivada de uma vontade nova de manipular e controlar a natureza. Está aqui, segundo Alves, a semente de um pensamento efetivamente científico. E o início de um conflito entre um universo encantado e um que solicita e exige a previsão e o controle não mais divino mas humano.

Carl Sagan ${ }^{3}$, diz que a ciência é mais do que um corpo de conhecimento, é um modo de pensar. A ciência é uma tentativa, em grande parte bem sucedida, de compreender o mundo, de controlar as coisas, de ter domínio sobre nós mesmos, de seguir um rumo seguro.

A ciência por si mesma não pode defender linhas de ação humana, mas certamente pode iluminar as possíveis conseqüências de linhas alternativas de ação. O modo científico de pensar, ao mesmo tempo imaginativo e disciplinado, é fundamental para o seu sucesso. 0 uso de um método que permite e sustente a dúvida sistemática nos convida a acolher os fatos, mesmo quando eles não se ajustam às nossas preocupações. Aconse- 
Iha-nos a guardar hipóteses alternativas em nossas mentes, para ver qual se adapta melhor à realidade.

A ciência também deve ser transmitida a todos os cidadãos, ela pode ser o caminho propício para vencer a pobreza e o atraso nas nações emergentes. Ela faz funcionar as economias nacionais e a civilização global. Nos esclarece sobre questões mais profundas das origens, naturezas e destinos de nossa espécie, da vida, de nosso planeta, do Universo. Os valores da ciência e da democracia são concordantes, em muitos casos indistingüíveis. A ciência confere poder a qualquer um que se der ao trabalho de aprendê-la. Ela se nutre do livre intercâmbio de idéias.

O mesmo autor não acha que seja difícil de ensinar porque os seres humanos não estão preparados para esse tipo de conhecimento, ou porque ela nasceu apenas de um acaso feliz, ou porque de modo geral, não temos bastante inteligência para compreende-la. Ele acha que a inclinação da ciência está profundamente entranhada em nós, em todas as épocas, lugares e culturas. Tem sido o meio de sobrevivência do ser humano. É nosso direito hereditário. Quando nos privarmos da ciência, estaremos nos roubando das ferramentas necessárias para administrarmos o nosso futuro.

Mas esta fé na ciência, especialmente no que se reconhece como ciência moderna, precisa ser qualificada em função do preço que se paga ao tomá-la como modelo hegemônico do conhecimento. Se a ciência produz um conhecimento que pode ser discutido e criticado, sua produção não está protegida da esfera do poder, das relações de dominação que atravessam todas os relacionamentos humanos e que transformam um conhecimento social e ideologicamente produzido em um conjunto de saberes naturalizado que contribui para a dominação ${ }^{4,5}$.

Se o ensino da Ciência precisa ser relacionado a esta dimensão social e humana ${ }^{6}$, a forma como ele se dá em função das condições bastante concretas em que se oferece a formação acadêmica universitária não parece contribuir para colocar o estudante dentro deste conflito. No caso dos estudantes de Psicologia, especialmente, situação que se repete nos cursos superiores da área de saúde, o aluno é colocado - e se coloca - não como protagonista de um embate entre diferentes formas de se conhecer ou de se relacionar com o conhecimento, mas apenas como um receptor de informação profissionalizante ${ }^{7}$. Em pesquisa que busca avaliar os resultados acadêmicos dos cursos universitários $^{8}$, um dos resultados mais significativos trata efetivamente de um descompasso entre o conhecimento sobre a prática, de um lado, e, de outro, questões metodológicas e epistemológicas, instrumentos típicos do embate científico. Em outra investigação sobre a imagem do profissional de psicologia ${ }^{9}$, os próprios estudantes afirmam como a formação acadêmica levaria ao esvaziamento dos aspectos morais e valorativos em favor daqueles que caracterizam a racionalidade de sua atuação profissional.
Pode-se dizer, como visto acima, que o conhecimento religioso é dogmático, não testável, depende de crença/ fé e o conhecimento científico é replicável, fidedigno, generalizável, embora sujeito a pressões ideológicas. Ainda assim, ciência e religião são ações humanas divergentes ou convergentes enquanto ao conhecimento?

O objetivo deste trabalho foi estudar junto a aluno de Psicologia relações entre as representações sociais ${ }^{10}$ de ciência e religião. Tendo em vista que o curso superior de Psicologia oferece novos referenciais, condições de re-significar as experiências cotidianas que demandam escolhas e posicionamentos em relação a condutas e valores pessoais, e que o aprendizado da ciência constituído no decorrer do curso colocaria em xeque muitos dos conceitos que trazemos com a nossa crença religiosa, a pesquisa pretendeu responder se o aprendizado da ciência muda as formas de vivenciar o sentimento de religiosidade dos alunos, levando os alunos de Psicologia a encontrar o limite entre ciência e religião ou se sua formação "científica" oferece apenas o aprendizado de mais uma prática que será utilizada profissionalmente.

\section{MÉTODOS}

A amostra foi constituída de 5 sujeitos de classe média, com idades entre 20 e 45 anos, alunos do $3^{\circ}$ ano (de cinco) do curso de Psicologia de uma rede particular de ensino, localizada na região metropolitana de São PauIo. Como instrumento de coleta de dados foi utilizada entrevista semi estruturada, na qual o entrevistador tem ampla liberdade para intervir sobre o fluxo de pensamentos do entrevistado ${ }^{11}$. A partir de um roteiro pré-estabelecido, foram investigados, de um lado, o conhecimento sobre a religião, sua importância e finalidade atribuídas pelo sujeito, suas experiências religiosas, e, de outro, a formação e conhecimento científico pessoal, a importância atribuída à ciência, e finalmente o entendimento do sujeito sobre a interferência da inserção acadêmica na relação com a religião e a ciência. As entrevistas, únicas, foram gravadas. Todos os sujeitos tiveram acesso a Termo de Consentimento Livre e Esclarecido.

O material coletado foi submetido à análise discursiva de acordo com Bernardes ${ }^{12}$. Neste sentido procedeu-se a leitura do material com a finalidade de destacar significados relativos ao fenômeno pesquisado que foram listados, classificados em categorias e transformados num texto consistente com o mesmo.

\section{RESULTADOS}

A religião dentro da vida dos pesquisados assume importância de graus variados, mas, via de regra, é apresentada como base da vida. Ela recebe um padrão de inquestionabilidade, de sentimentos únicos, e está associada ao sentir-se bem. Em todos os sujeitos aparece 
a presença de fé, o que não implica necessariamente a freqüência a igrejas, cultos ou sessões. Em relação à freqüência, a importância indicada para alguns dos entrevistados fica relativizada pelo tempo que tem disponível para isto.

A prática religiosa aqui entendida como viver a religião e seus ensinamentos, foi descrita por um dos membros como vivida no dia a dia, e em família. A importância da prática no contexto de vida apareceu como de fundamental importância, trazendo paz de espírito, calma, sensações de se sentir bem, de necessidade de se pensar nela para poder meditar, como alimento para a alma ou para o espírito e como algo que os protegesse. As respostas evidenciam um movimento que distancia os indivíduos das práticas religiosas institucionalizadas.

Visão ampla da vida, visão maior do mundo, satisfação, resposta, complemento, ajuda, proteção, paz, tranqüilidade, necessidade de se agarrar a algo, respostas a perguntas que não fazem sentido, conhecimentos filosóficos, tudo isso é percebido como diferentes formas de conhecimento que a religião traz para os entrevistados.

Por outro lado, ao tratar do conhecimento científi$\mathrm{co}$, os entrevistados dizem estar tendo o primeiro contato com a ciência nesta formação acadêmica. Isto se evidencia também no ambiente familiar que, eventualmente possui alguém com alguma experiência acadêmica, o que se dá em geral apenas com o entrevistado.

A ciência ofereceria para eles um tipo de conhecimento mais concreto, mais objetivo. Conhecimentos que, no entanto, não interferem na sua fé; a ciência é algo que se tem para buscar respostas para suas dúvidas, e como comprová-las através de fatos. Ciência como forma de compreender o mundo, conhecimentos teóricos, mas sem abalar convicções mais profundas. Eles identificam alguma interferência da ciência sobre a religião apenas no começo da formação acadêmica, conflitando com crenças antigas. Mas, no decorrer do curso, aprendem a separar ciência da religião, de uma forma que estas não mais confluem. Para alguns deles, inclusive, essa interferência não se realiza, e a ciência aparece oferecendo a possibilidade de se buscar mais respostas, com esta trazendo uma outra "via do olhar", complementando, de alguma forma, o conhecimento religioso. Eles informam terem encontrado conexões da ciência com a religião, como se uma explicasse a outra, uma complementando a outra.

\section{DISCUSSÃO}

As representações dos sujeitos acerca do conhecimento religioso convergem com aquela indicada na revisão da literatura, quando o sentido da religião está associado a tentativa de se encontrar sentido e valor na vida, como explicações de eventos do universo por um poder espiritual, e o esforço para se pensar a realidade a partir da exigência de que a vida faça sentido. Também, como Alves ${ }^{2}$, encontramos que as teias religiosas são tecidas em torno dos problemas individuais e sociais como necessidade de paz, proteção, resolução de lutas entre homens, harmonia com a natureza, etc. Ainda, o conhecimento que vem da ciência é dogmático.

É o senso comum ainda que determina a representação de ciência: ela não é compreendida em oposição a outras formas de conhecer, mas oferece um conhecimento complementar, como uma também tentativa, em grande parte bem sucedida, de compreender o mundo, de controlar as coisas, de ter domínio sobre nós mesmos, de seguir um rumo seguro. A ciência não se apresenta como empreendimento coletivo e social, como algo que confere poder a qualquer um que se der ao trabalho de aprendê-la.

Os depoimentos reconheceram claramente distinção entre ciência e religião. Todos os entrevistados mostraram-se conscientes da necessidade de religião em suas vidas, crença essa que não necessita de templos ou instituições, mas que se encontra entranhada dentro dos sujeitos. E isto, por outro lado, é o que parece indicar uma convergência entre ciência e religião: trata-se de um conhecimento individualizado, pessoal, algo que, em última instância não está disponível para a crítica e para a reconstrução.

Compartimentos separados, que se entrecruzam às vezes, que não se contrapõem. A fé religiosa reina soberana, com linguagem diferente da ciência, que responde às necessidades afetivas e aos desejos da pessoa, faz parte da vida, mora no registros emocional e social do indivíduo. Neste sentido é que se pode compreender como, de acordo com os entrevistados, o contato com a ciência não muda o sentimento de religiosidade. Esse sentimento de religiosidade recebe uma carga de conflitos, que logo é superado, passando a conviver lado a lado, ciência e religião. Todos os entrevistados reconheceram a possibilidade de compatibilidade entre ciência e religião, como sistemas de conhecimento.

Se os objetivos em relação ao aprendizado da ciência como proposta para a aquisição de uma nova postura em relação ao conhecimento não foram alcançados, a formação acadêmica não tem suprido essa necessidade de conflito para que a ciência se estabeleça como nova forma de se pensar, uma nova "via do olhar".

Assim, o conhecimento é tomado também de forma totalizante, fundamentalista, como algo pronto e dogmático. O aluno parece não se dar conta da sua inserção no ambiente científico como alguém que poderia interferir sobre um determinado campo do conhecimento. Não há uma atitude crítica junto a este processo de aprendizagem, mas apenas uma assimilação que 
pretende encontrar um lugar para este conhecimento "novo" junto aquele que já vem das suas práticas religiosas. Daí esta busca por uma complementaridade do conhecimento. Vale indicar que esta representação do conhecimento científico se faz, ao que tudo indica, não tendo o próprio universo reificado da ciência como referente, isto é, a aprendizagem se faz - e não pode ser diferente - tendo como referência um universo consensual de conhecimento, o universo do senso comum do grupo de referência destes alunos, e que tem como paradigma de conhecimento sobre o mundo, em grande medida, o conhecimento religioso. A questão do método, tão própria do conhecimento científico, e que permite que o pesquisador exerça sua prerrogativa de duvidar de um conhecimento que tem origem nele mesmo e nos outros está absolutamente abandonada, ou sequer foi apreendida pelos alunos. Eles se vêem diante de conhecimentos que, quando compreendidos, são tomados como mais uma parcela de um conhecimento que é único e definitivo e não construído socialmente, marcado pela ideologia e pelo conflito de discursos sobre a verdade 5 .

Assim, se é possível dizer sobre as dificuldades em se construir uma posição científica em alunos do curso de Psicologia, também deve-se olhar para a formação como contaminada pela proposta de um conhecimento que, ainda que nomeado como científico, tem uma dimensão totalizante, opondo professor e aluno numa batalha pelo domínio sobre um discurso que um tem e o outro não.

\section{REFERÊNCIAS BIBLIOGRÁFICAS}

1. Armstrong K. Uma História de Deus. São Paulo, Cia das Letras, 1999.

2. Alves R. O que é Religião. São Paulo: Brasiliense, 1992.

3. Sagan C. O Mundo Assombrado Pelos Demônios. São Paulo: Cia das Letras, 2002,

4. Luz M. Natural, Racional, Social: razão médica e racionalidade científica moderna. $2^{a}$ edição. São Paulo: Hucitec, 2004, 209p.

5. Minayo MCS. O desafio do conhecimento: pesquisa qualitativa em saúde. $8^{a}$ edição. São Paulo: Hucitec, 2004, 269p.

6. Bagnato MHS. Fazendo uma travessia: em pauta a formação dos profissionais da área de sáude. In: Bagnato MHS, Cocco MIM, de Sordi MRL (orgs) Educação, saúde e trabalho: antigos problemas, novos contextos, outros olhares. Campinas: Editora Alínea, 1999, p.9-24.

7. Eisenlohr MGV. Formação de Alunos em Psicologia- Uma Possibilidade para Educadores. Dissertação de Mestra-

\section{CONCLUSÕES}

Tendo em vista esses resultados, conclui-se que a ciência não interfere nas crenças mais profundas e arraigadas do aluno de Psicologia. Sendo a religião, religiosidade, fé, aspectos que cumprem funções individuais e sociais, vêse a necessidade da formação de mais áreas de conflito no curso de Psicologia, para que o futuro psicólogo, realmente veja na ciência e na religião, uma outra "via do olhar", que no arranjo da vida, se encontre a possibilidade de convivência da religião e da ciência, pois o hábito, a pressão social, os estados psicológicos, atitudes, conceitos, pré-conceitos e outros tantos, são aspectos que influem concretamente na vida dos futuros psicólogos.

A formação acadêmica não produz conflitos suficientes nem para a instalação da "fé" na ciência, muito menos para a incorporação de um instrumental crítico sobre o conhecimento. Ela é representada apenas como mais uma prática que não conduz os alunos à formação de pensadores, favorecendo apenas a formação de praticantes que apenas a reproduzem, não criam, não aprendem a pensar e a questionar. Entendemos esta condição como extremamente série, exigindo ações concretas sobre a formação científica que emana da cultura universitária contemporânea em tempos que neo-liberais, desde que este movimento atravessa a universidade e situa os futuros profissionais como cidadãos sem os recursos que sustentam um posicionamento participativo nas suas realidades cotidianas, e de responsabilidade sobre a manutenção ou a transformação das condições sociais e humanas do país.

do apresentada ao Instituto de Psicologia da Universidade de São Paulo, 1997.

8. Landeira F, Primi R. Comparação do Desempenho entre Calouros e Formandos de Psicologia no Provão 2.000". Psicologia Reflexão e Crítica 2002; 15(1): 219-234.

9. Bettoi W, Mathias L. Pesquisa "Entrevistas com Profissionais como Atividade de Ensino-Aprendizagem desejável na formação do Psicólogo". Psicologia Reflexão e Critica 2002; 15(3): 613-624.

10. Moscovici Serge. Representações Sociais. Petrópolis: Vozes, 2003.

11. Bleger JÁ. entrevista psicológica: seu emprego no diagnóstico e na investigação. In: Temas de Psicologia: Entrevistas e Grupos. São Paulo: Martins Fontes, 1984, p7-41.

12. Bernardes NMG. Análise Compreensiva de Base Fenomenológica e o estudo da experiência vivida de crianças e adultos. Educação 1991; 14(20):15-40. 